\title{
CRESCIMENTO E DESENVOLVIMENTO DA PLANTA DANINHA CAPIM-CAMALOTE ${ }^{(1)}$
}

\author{
SAUL JORGE PINTO DE CARVALHO ${ }^{(2)}$; MURILO SALA MOREIRA ${ }^{(3)}$; \\ MARCELO NICOLAI (2); RAMIRO FERNANDO LÓPEZ OVEJERO ${ }^{(2)}$; \\ PEDRO JACOB CHRISTOFFOLETI ${ }^{(4)}$; DANIEL MEDEIROS ${ }^{(5)}$
}

\begin{abstract}
RESUMO
O capim-camalote (Rottboelia exaltata L.f.) é uma planta daninha com rápida disseminação nas áreas canavieiras do Brasil, causando significativas perdas de produtividade na cultura. Assim, esta pesquisa teve por objetivo avaliar o crescimento, o desenvolvimento vegetativo e a capacidade reprodutiva do capim-camalote, como mecanismo de melhoria do manejo a ser adotado. O experimento foi desenvolvido em casa de vegetação da ESALQ/USP, entre julho e outubro de 2004, quando foram realizadas 14 avaliações periódicas de crescimento, determinando-se: massa fresca e seca (total, parte aérea e raízes), área foliar e fenologia das plantas. Realizou-se a contagem do número de rácemos florais de 16 plantas e do número de sementes de 100 rácemos após florescimento. Pôde-se observar um rápido crescimento inicial das plantas, de tal forma que o início do florescimento ocorreu aos 49 dias após a semeadura. No fim do ciclo, verificaram-se nas plantas valores próximos a $120 \mathrm{~g}, 25 \mathrm{~g}$ e $1.600 \mathrm{~cm}^{2}$ de massa fresca total, massa seca total e área foliar, respectivamente. Na ocasião das contagens, as plantas haviam emitido, em média, o total de 163 rácemos com 12 sementes cada uma, o que corresponde a mais de 2.000 sementes por planta. Pelos resultados alcançados verifica-se elevada capacidade de crescimento e habilidade reprodutiva do capim-camalote, explicando as razões que fazem dessa planta daninha um novo problema em potencial para a agricultura brasileira.
\end{abstract}

Palavras-chave: biologia, Rottboelia exaltata, crescimento, reprodução.

\section{ABSTRACT \\ GROWTH AND DEVELOPMENT OF THE WEED ITCHGRASS (ROTTBOELIA EXALTATA L.f.)}

Itchgrass (Rottboelia exaltata L.f.) is a weed that has presented fast dissemination in sugar-cane fields in Brazil, causing significant yield losses to the crop. Therefore, this research had the objective of evaluating the growth, vegetative development and reproductive capacity of the species, as a mechanism of improving the management to be adopted. The experiment was conducted in the greenhouse of ESALQ/ USP, Piracicaba, State of São Paulo, Brazil, during the months of July to October 2004; when 14 periodic evaluations of growth were done, for determination of: fresh and dry weight (total, shoot and roots), leaf area and phenology. After flowering, the number of racemes of 16 plants, and the number of seeds of 100 racemes were evaluated. It was observed a fast initial growth of the plants, once the flowering occurred 49 days after seeding. About the end of the cycle, plants showed values near than $120 \mathrm{~g}, 25 \mathrm{~g}$ and $1600 \mathrm{~cm}^{2}$ of total fresh weight, total dry weight and leaf area, respectively. On average, plants emitted a total of 163 racemes with 12 seeds each, that corresponds to more than 2,000 seeds per plant. These results showed the high growth capacity and reproductive hability of R. exaltata, explaining the reasons that make this weed a new potential problem for Brazilian agriculture.

Key words: biology, Rottboelia exaltata, growth, reproduction.

( $\left.{ }^{1}\right)$ Recebido para publicação em 29 de novembro de 2004 e aceito em 15 de julho de 2005.

$\left(^{2}\right)$ Pós-Graduandos da ESALQ/USP. E-mail: sjorge@esalq.usp.br, marcelon@esalq.usp.br, rfloveje@esalq.usp.br

( $\left.{ }^{3}\right)$ Aluno de Graduação da ESALQ/USP. E-mail: murilosm@esalq.usp.br

$\left({ }^{4}\right)$ Departamento de Produção Vegetal, ESALQ/USP. E-mail: pjchrist@esalq.usp.br

$\left({ }^{5}\right)$ BASF S.A. - Cana-de-açúcar; E-mail: daniel.medeiros@basf-sa.com.br 


\section{INTRODUÇÃO}

Originário da Ásia, provavelmente da Índia, o capim-camalote (Rottboelia exaltata L.f.) já esta presente nas mais diversas partes do mundo. No Brasil, ocorre com maior freqüência na Região Norte, contudo, existem focos de ocorrência no Estado de São Paulo e na Região Centro-Oeste. Planta da família Poaceae, possui ciclo anual ou perene, dependendo das condições ambientais. Reproduz-se a partir de sementes podendo, também, ser multiplicada por pedaços de caule, os quais possuem gemas em seus nós (KissmanN, 1997).

Trata-se de uma planta muito vigorosa e prolífica, e uma única planta chega a emitir até 100 perfilhos, capazes de produzir 15.000 sementes que podem ficar dormentes nos solos por até quatro anos (LORENZI, 2000). Devido à sua elevada adaptabilidade ecológica, apresenta ocorrência nos mais diversos ambientes produtivos. Na região do município de Campos dos Goytacazes, Estado do Rio de Janeiro, tem-se tornado grave problema nas áreas produtoras de cana-de-açúcar, sobretudo devido a sua elevada competitividade e altas densidades de infestação. Embora apresente crescente importância, poucos são os estudos envolvendo essa planta daninha no Brasil.

Estima-se que, considerando-se as distintas regiões canavieiras do mundo, existam cerca de 1.000 espécies de plantas daninhas habitando o agroecossistema da cana-de-açúcar (ARÉVALO, 1979). De todas as espécies de plantas daninhas, Holm et al. (1977) classificam o capim-camalote como uma das 18 piores do mundo, na cultura da cana-de-açúcar, a espécie está entre as doze piores.

A interferência causada pela presença das plantas daninhas na cultura da cana-de-açúcar pode reduzir a quantidade de colmos colhidos ou mesmo o número de cortes economicamente viáveis (LORENZI, 1988). Estudos demonstram reduções de produtividade nos canaviais variando de $20 \%$ (KuvA et al., 2000) até 86\% (Lorenzi, 1983). Arévalo e BERTONCINI (1994) atribuem perdas de rendimento até de $100 \%$ em cana-planta e até $80 \%$ em cana-soca em decorrência da competição da cultura com altas infestações de Rottboelia exaltata.

Segundo FERNÁNDEZ (1982) uma das maiores limitações que existem para a criação de programas de manejo integrado de plantas daninhas é a carência de conhecimentos básicos sobre a biologia e a ecologia dessas plantas. A Weed Science Society of America (WSSA) ressaltou que o conhecimento sólido sobre a biologia das plantas daninhas é a base para seu efetivo manejo, por meio de sistemas de manejo integrado (Oliver, 1997).

Segundo Benicasa (1988), o uso de análises de crescimento ainda é o meio mais simples e preciso para inferir a contribuição de diferentes processos fisiológicos para o crescimento vegetal. Mediante esse tipo de análise, torna-se possível o conhecimento da cinética de produção de biomassa das plantas, sua distribuição e eficiência ao longo da ontogenia.

Estudos sobre o crescimento e o desenvolvimento das plantas daninhas fornecem informações sobre os diferentes estádios fenológicos e padrões de crescimento que tornam possível a análise do comportamento dessas plantas perante os fatores ecológicos, bem como sua ação sobre o ambiente, principalmente quanto a sua interferência sobre outras plantas (LUCCHESI, 1984). RADOSEVICH et al. (1997) afirmam que a produção de massa seca total bem como o acúmulo da área foliar são reconhecidos como processos básicos no crescimento vegetal.

Assim, esta pesquisa teve por objetivo acompanhar a fenologia, o crescimento e o desenvolvimento, bem como avaliar as características reprodutivas do capim-camalote (Rottboelia exaltata L.f.).

\section{MATERIAL E MÉTODOS}

O experimento foi realizado em casa de vegetação do Departamento de Produção Vegetal da Escola Superior de Agricultura "Luiz de Queiroz" ESALQ/USP, de julho a outubro de 2004. Inicialmente, as sementes de Rottboelia exaltata foram colocadas para germinar em caixas plásticas (tipo "Gerbox"), preenchidas com areia lavada, dentro de câmara de germinação com fotoperíodo de 8 horas de luz, a $30{ }^{\circ} \mathrm{C}$ e 16 horas de escuro, a $20^{\circ} \mathrm{C}$. Após a emergência, quando as plântulas estavam no estádio de coleoptilo, foram transplantadas para os vasos onde permaneceram até o fim do experimento, uma planta por vaso.

As parcelas experimentais constaram de vasos com capacidade para $3 \mathrm{~L}$, preenchidos também com areia lavada. Diariamente, os vasos foram irrigados até o ponto de drenagem e, após o reequilíbrio hídrico das parcelas, administrou-se $100 \mathrm{~mL}$ de solução nutritiva em cada vaso. A solução nutritiva utilizada continha $\left(\mathrm{mg} \mathrm{L}^{-1}\right)$ : N - 210; P - 150; K - 310; $\mathrm{Ca}-186 ; \mathrm{S}-32 ; \mathrm{Mg}-19 ; \mathrm{Zn}-0,5 ; \mathrm{B}-0,3 ; \mathrm{Fe}-5$; Mn - 0,4; Cu - 0,5 e Mo - 0,05.

O delineamento experimental adotado foi do tipo inteiramente casualizado, com 14 tratamentos e quatro repetições. Durante todo o experimento, foram 
realizadas 14 avaliações, respectivamente aos 6,17 , $22,28,34,40,45,49,55,61,69,76,83$ e aos 90 dias após semeadura (DAS). Quatro plantas (repetições) foram amostradas (método destrutivo) aleatoriamente em cada avaliação; passaram por lavagem em água corrente, sobretudo para a retirada da areia remanescente nas raízes e, em seguida, tiveram suas variáveis analisadas. Foram avaliadas fenologia, massa fresca total $(F W t)$, massa fresca da parte aérea $(F W a)$, massa fresca das raízes $(F W r)$ e área foliar $(L a)$. Todo o material amostrado foi secado até a obtenção de peso constante, quando as demais variáveis de interesse foram mensuradas: massa seca total $(W t)$, massa seca da parte aérea $(W a)$ e massa seca das raízes $(W r)$. O estádio fenológico foi definido quando $50 \%$ + 1 das plantas apresentavam determinada característica de desenvolvimento. Todos os valores reais de área foliar do experimento foram obtidos com o uso do aparelho LI - 3100 Area Meter (LI-COR, inc., Lincoln, Nebraska, USA).

Durante o transcorrer do experimento, 16 plantas tiveram seus racemos florais colhidos e contados à medida que seus artículos apresentavam-se em processo de maturação. Para a estimativa do número total de sementes produzidas por planta, 100 racemos foram selecionados aleatoriamente e tiveram seus artículos contados a fim de se obter o número médio de artículos produzidos por rácemo. Considerou-se como semente todo artículo adequadamente formado.

As variáveis quantitativas relacionadas com o crescimento da planta foram analisadas estatisticamente com a aplicação do teste F sobre a análise da variância seguido da aplicação de regressões não-lineares do tipo logística, com o objetivo de modelar dos dados sob a forma de equações. O modelo logístico adotado foi desenvolvido por STREIBIG (1988):

$$
y=\frac{a}{\left[1+\left(\frac{x}{b}\right)^{c}\right]}
$$

Sendo: $y$ é a variável resposta de interesse, $x$ é o número de dias acumulados e $a, b$, e $c$ são parâmetros estimados da equação, de tal forma que $a$ é a amplitude existente entre o ponto máximo e o ponto mínimo da variável; $b$ é o ponto de inflexão da curva e corresponde ao número de dias necessários para a ocorrência de $50 \%$ de resposta da variável e $c$ é a declividade da curva ao redor de $b$.
Com os valores estimados pela equação logística para a variável massa seca total $(W t)$ pôdese calcular a taxa de crescimento absoluto ( $G$, g dia- 1 ), a partir da fórmula: $\mathrm{G}=\left(W t_{2}-W t_{1}\right) /\left(t_{2}-t_{1}\right)$; em que $W t_{2}$ e Wt1 são as massas secas totais de duas amostras sucessivas e $t 2$ e $t 1$ são os dias decorridos entre as duas observações. Com os mesmos dados calculouse, também, a taxa de crescimento relativo ( $R, g$ g- 1 dia-1), a partir da fórmula: $\mathrm{R}=(\ln W t 2-\ln W t 1) /(t 2-t 1)$. Correlacionando-se os dados de área foliar e massa seca total obteve-se a razão de área foliar, calculada por: $\mathrm{F}=L a / W t$; em que $L a$ é a medida de área foliar obtida para a respectiva amostra de Wt (HUNT, 1990; Aguilera et al., 2004).

\section{RESULTADOS E DISCUSSÃO}

Durante todo o experimento, as plantas de Rottboelia exaltata mantiveram-se bastante vigorosas e com rápido crescimento inicial. Aos 28 DAS já se encontravam em estádio de perfilhamento, permanecendo sob pleno desenvolvimento vegetativo até os 45 DAS, quando teve início a fase reprodutiva com a definição do estádio fenológico de emborrachamento / pré-florescimento (Tabela 1). O florescimento ocorreu aos 49 DAS com a emissão dos primeiros racemos florais; as plantas mantiveram-se em florescimento, por meio da emissão contínua de novos racemos pelo colmo principal e posteriormente pelos perfilhos, até o fim do experimento. Para as localidades de Tucumán - Argentina e "Valle Del Cuaca" - Colômbia, Arévalo e BERTONCINI (1994) constataram valores para o início do florescimento oscilando entre 45 e 56 dias respectivamente.

Os parâmetros $a, b$ e $c$ do modelo logístico, para todas as variáveis do experimento estão apresentados na tabela 2. Esses parâmetros foram necessários à elaboração dos gráficos e ao ajuste dos dados de acúmulo de massa fresca, massa seca e área foliar do capim-camalote ao longo de seu ciclo de desenvolvimento.

O acúmulo de massa fresca observado demonstra a elevada capacidade que esta planta daninha possui em produzir fitomassa. Pôde-se observar que aos 49 DAS, na ocasião do florescimento, as plantas possuíam, em média, valores próximos de 26,5 g de massa fresca total (FWt), sendo, aproximadamente $20 \mathrm{~g}$ correspondentes à participação da massa fresca da parte aérea $(F W a)$ e os demais 6,5 $\mathrm{g}$ correspondentes à participação da massa fresca das raízes $(F W r)$. Menos de 30 dias após o início do florescimento, as plantas já estavam com valores de massa fresca cerca de 4,7 vezes maiores, alcançando índices próximos de $120 \mathrm{~g}$ de $F W t$, com a participação de aproximadamente 80 e $35 \mathrm{~g}$ para $F W a$ e $F W r$ respectivamente (Figura 1 ). 
Acredita-se que a distribuição proporcional da matéria seca nas diferentes partes constituintes das plantas se deve ao processo fisiológico da translocação de fotoassimilados ao longo do ciclo de desenvolvimento das espécies (AguiLera et al., 2004). No início do ciclo, pôde-se observar maior participação da massa das raízes com relação à massa total, evidenciando a fisiologia das plantas em iniciar seu crescimento colonizando o espaço e garantindo a adequada fixação no substrato. Contudo, a participação das raízes foi reduzida ao longo do ciclo, sobretudo em conseqüência da elevada produção de massa pela parte aérea, suprida pelos recursos provenientes do sistema radicular; resultados semelhantes foram relatados por BIANCO et al. (2004).

A habilidade dessa planta daninha em acumular fitomassa é uma das principais características biológicas da espécie que determina sua competitividade com as culturas agrícolas.

O rápido desenvolvimento da estrutura radicular com posterior formação de parte aérea favorece a dominação do espaço em que a planta está se desenvolvendo, principalmente em função da maior taxa de absorção de água e nutrientes com crescente interceptação da radiação incidente.

Tabela 1. Estádio fenológico $(50 \%+1)$ das plantas do capim-camalote; data e dias após semeadura (DAS). Piracicaba (SP), 2004

\begin{tabular}{lcl}
\hline Data & DAS & Estádio Fenológico \\
\hline 16 jul & Semeadura & - \\
22 jul & 6 & Transplante - Coleóptilo \\
2 ago & 17 & $1 .^{a}$ folha verdadeira \\
7 ago & 22 & 2 folhas verdadeiras \\
13 ago & 28 & 3 folhas verdadeiras, início do perfilhamento -1 perfilho \\
19 ago & 34 folhas verdadeiras e 2 perfilhos \\
25 ago & 40 & 4 folhas verdadeiras e 3 perfilhos \\
30 ago & 45 & 7 folhas verdadeiras e 3 perfilhos - emborrachamento \\
3 set & 49 & 7 folhas verdadeiras, 8 perfilhos, florescimento pleno \\
9 set & 55 & 8 folhas verdadeiras, 10 perfilhos, florescimento - maturação \\
15 set & 61 & 8 folhas verdadeiras, 10 perfilhos, maturação (colmo principal) \\
23 set & 69 & 8 fl., 12 perf., maturação / início da senescência (colmo principal) \\
30 set & 73 & 8 fl. verdadeiras, 12 perf., maturação / senescência (colmo principal) \\
7 out & 83 & 8 folhas verdadeiras, 12 perf., maturação / senescência (colmo principal) \\
14 out & 90 &
\end{tabular}

Tabela 2. Parâmetros do modelo logístico para as variáveis determinadas no experimento

\begin{tabular}{lcccc}
\hline \multirow{2}{*}{ Variável } & \multicolumn{3}{c}{ Parâmetros } \\
\cline { 2 - 5 }$F W t$ & $a$ & $b$ & $c$ & $\mathrm{r}^{2}$ \\
\hline$W a$ & 117,032 & 54,732 & $-10,508$ & 0,992 \\
$F W r$ & 82,220 & 55,176 & $-9,426$ & 0,993 \\
$W t$ & 33,753 & 53,940 & $-15,779$ & 0,964 \\
$W a$ & 25,351 & 55,968 & $-11,076$ & 0,991 \\
$W r$ & 18,214 & 57,195 & $-9,094$ & 0,997 \\
$\mathrm{La}$ & 6,964 & 54,071 & $-20,331$ & 0,976 \\
\hline
\end{tabular}




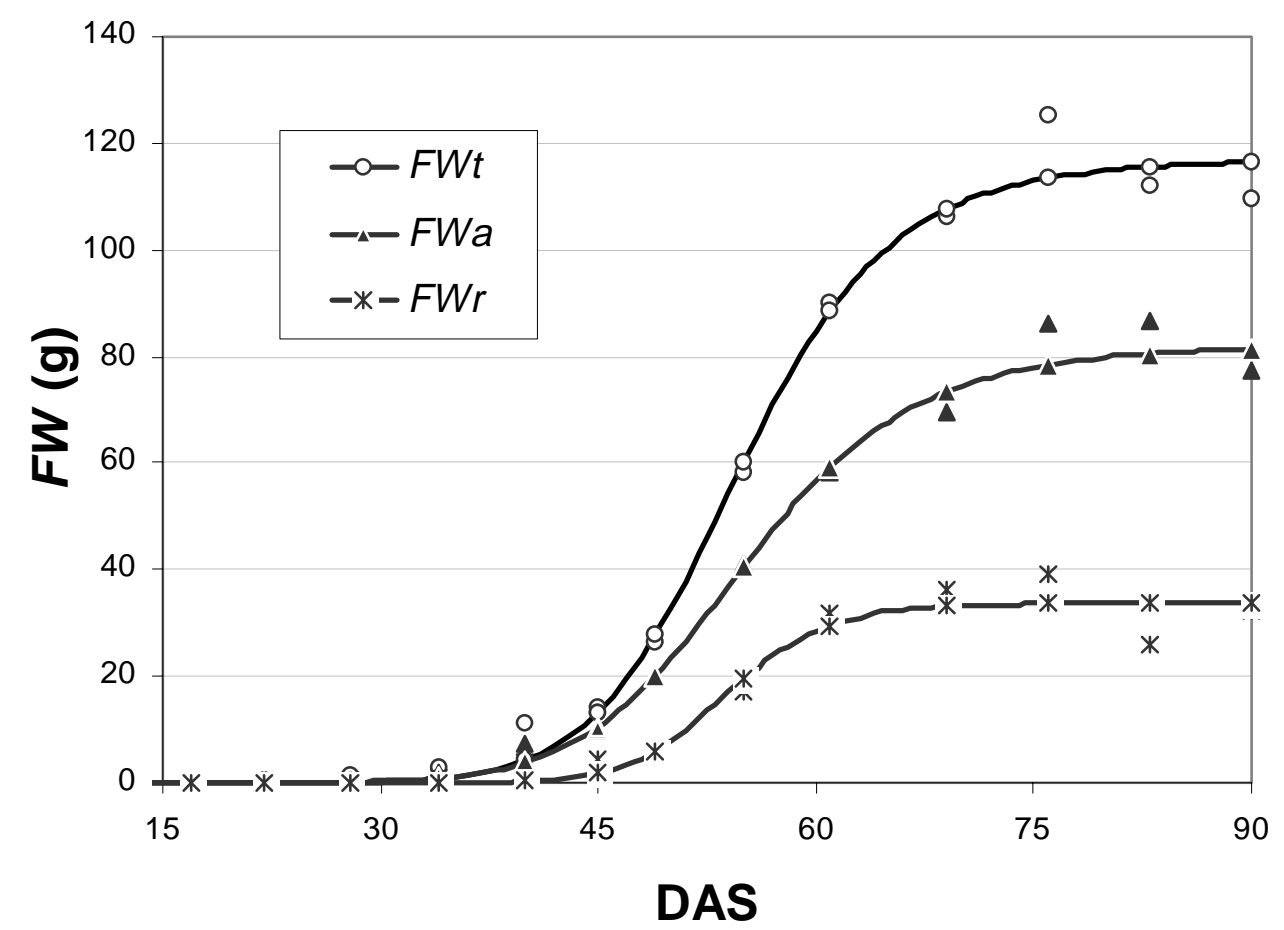

Figura 1. Médias observadas e ajustadas de massa fresca total ( $F W t)$, massa fresca da parte aérea $(F W a)$ e massa fresca das raízes $(F W r)$ das plantas de Rottboelia exaltata ao longo de seu ciclo de desenvolvimento. Piracicaba (SP), 2004.

O variável acúmulo de massa seca total $(W t)$ iniciou a estabilização próximo dos 80 DAS, com valores médios de 25 g planta-1 e participação de aproximadamente 18 e $7 \mathrm{~g}$ para a massa seca da parte aérea $(W a)$ e das raízes $(W r)$ respectivamente (Figura 2). A área foliar $(L a)$ acompanhou o ganho de massa da parte aérea, sendo o ponto de estabilização alcançado próximo dos 75 DAS, com aproximadamente $1.600 \mathrm{~cm}^{2}$ de área foliar por planta (Figura 3).

Segundo Paul e Elmore (1984), o capimcamalote é uma planta daninha que possui mecanismo fotossintético do tipo $C_{4}$, com ocorrência da enzima NADP-malato desidrogenase (NADP-ME). Segundo esses autores, a fotossíntese pelo ciclo $\mathrm{C}_{4}$ confere diversas características vantajosas às plantas, sobretudo em ambientes quentes e úmidos, como por exemplo baixo ponto de compensação de CO2, elevada taxa de fotossíntese quando em ambiente de alta disponibilidade de luz e baixa taxa de fotorrespiração. Essa característica da espécie pode explicar o vigoroso crescimento vegetativo e o rápido ciclo reprodutivo.

O fato de o capim-camalote realizar fotossíntese por meio do ciclo $\mathrm{C}_{4}$ favorece a presença da espécie em áreas de produção de cana-de-açúcar.
Essa cultura também apresenta ciclo fotossintético $C_{4}$, o que a torna uma espécie altamente competitiva com a comunidade daninha. Dessa forma, as plantas daninhas mais aptas à competição com a cana-deaçúcar, em geral, possuem alta eficiência fotoquímica e rápida ocupação do espaço, como é o caso de diversas espécies ciperáceas e poáceas, dentre estas o capim-camalote. A dispersão do capim-camalote nas várias regiões agrícolas brasileiras pode tornarse um problema crescente para a agricultura do país, sobretudo quando da infestação da espécie em culturas menos competitivas, com ciclo fotossintético do tipo $C_{3}$, como as culturas da soja e do feijão, por exemplo.

Os valores ajustados de massa seca e área foliar foram utilizados para o cálculo da taxa de crescimento absoluto, taxa de crescimento relativo e a razão de área foliar. A taxa de crescimento absoluto (G) fornece uma estimativa da velocidade média de crescimento das plantas ao longo do ciclo de desenvolvimento; a taxa de crescimento relativo (R) exprime o aumento em gramas de matéria seca por unidade de material presente em um período de observação e a razão de área foliar (F) é um componente morfofisiológico que expressa a área foliar disponível para a fotossíntese (Aguilera et al., 2004). 


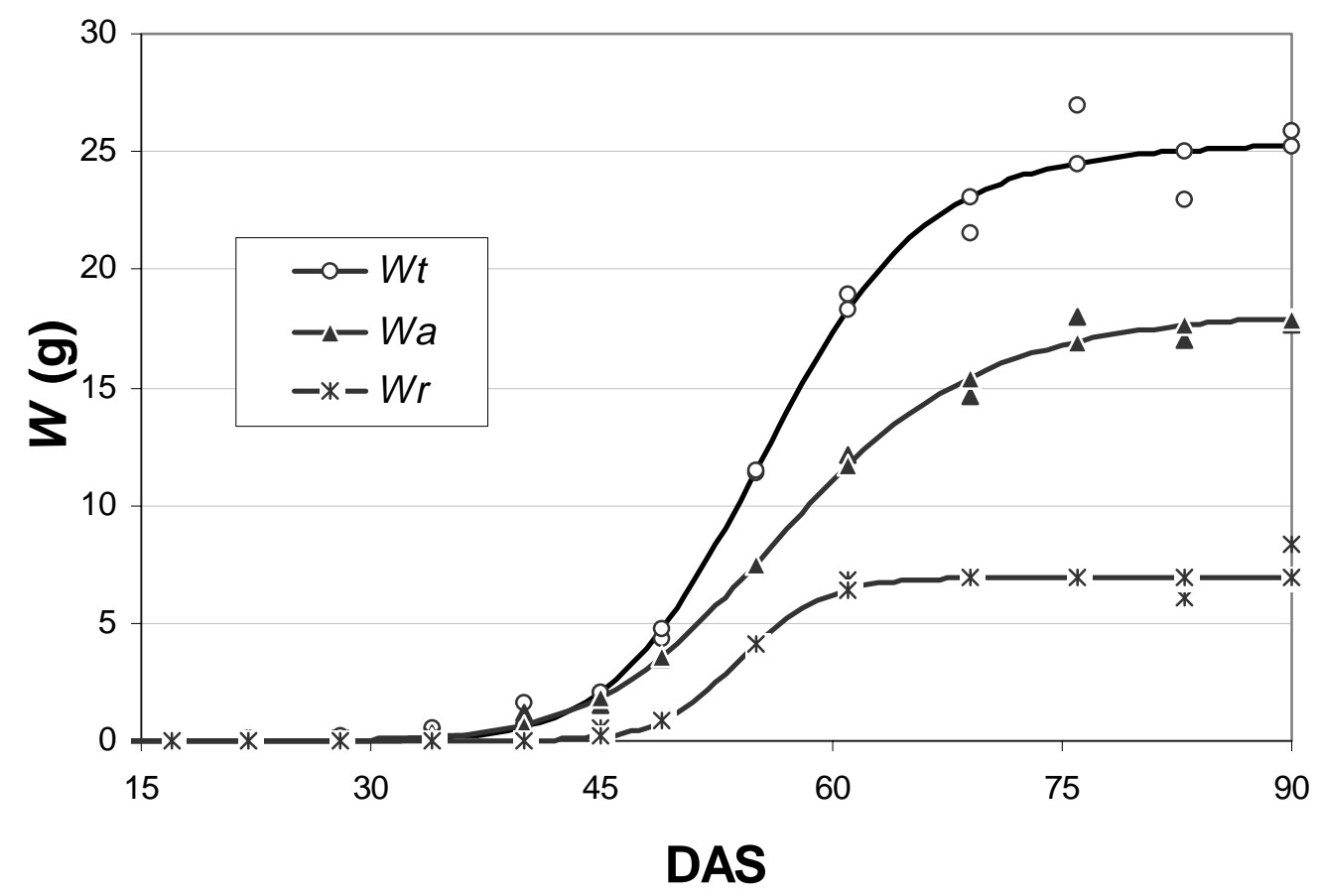

Figura 2. Médias observadas e ajustadas de massa seca total ( $W t$ ), massa seca da parte aérea ( $W a)$ e massa seca das raízes (Wr) das plantas de Rottboelia exaltata ao longo de seu ciclo de desenvolvimento. Piracicaba (SP), 2004.

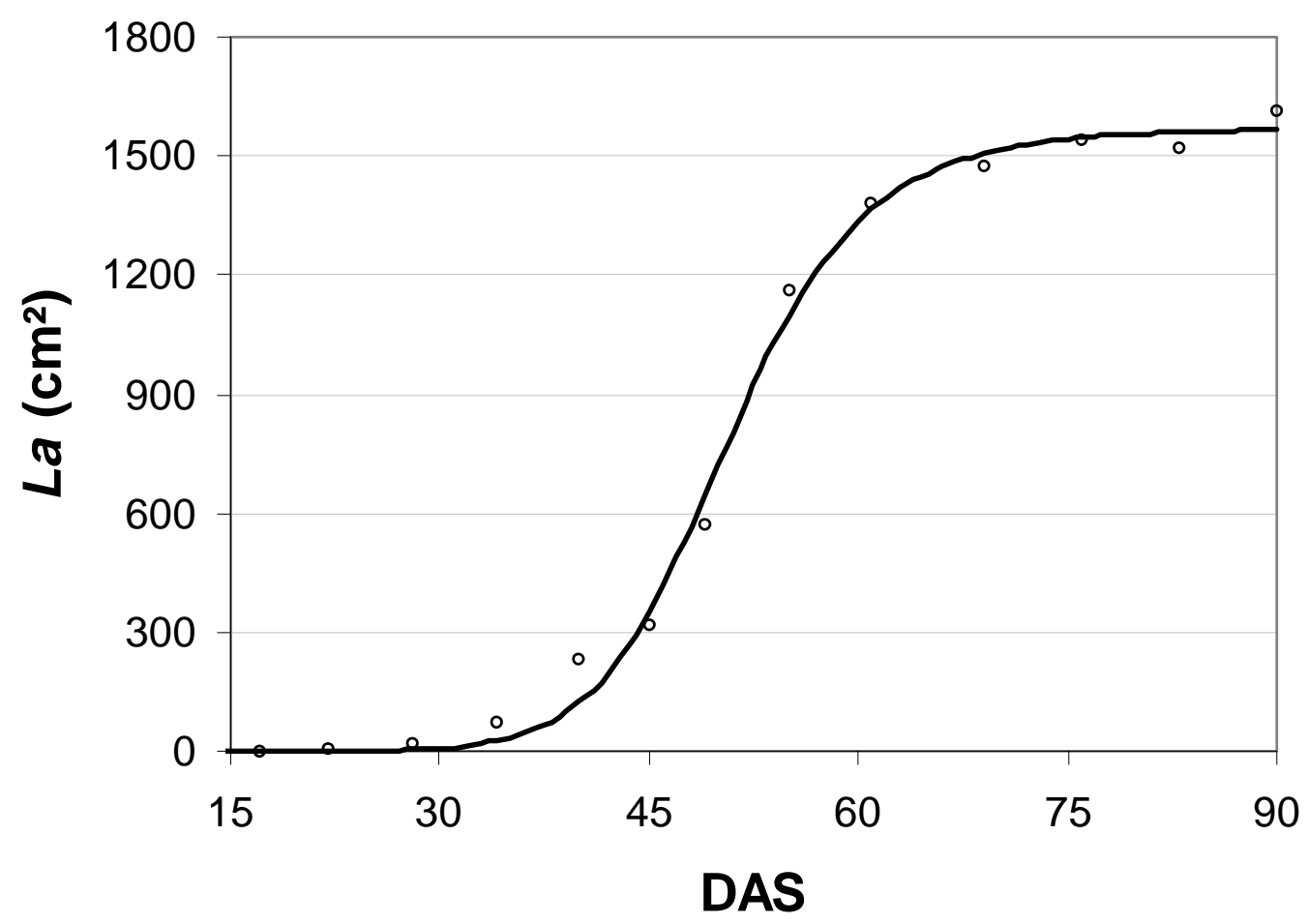

Figura 3. Média observada e ajustada de acúmulo de área foliar ( $L a$ ) das plantas de Rottboelia exaltata ao longo de seu ciclo de desenvolvimento. Piracicaba (SP), 2004. 
No caso da planta daninha Rottboelia exaltata, observou-se que os maiores valores nas estimativas de $\mathbf{R}$ e $\mathbf{F}$ ocorreram no início do desenvolvimento das plantas, com conseqüente queda ao longo do ciclo. $\mathrm{O}$ valor de $\mathrm{G}$ apresentou-se estável no início do ciclo com rápido aumento posterior em modelo de parábola, com pico próximo dos 60 DAS (Figuras 4, 5 e 6). Esses dados confirmam o rápido crescimento inicial da espécie, quando a planta mostrou-se especializada na dominação do espaço. O gráfico de $\mathbf{G}$ representa a projeção do acúmulo da massa seca total $(W t)$ em termos da diferença de massa existente em função do tempo. Assim, o ponto de máximo crescimento absoluto é refletido na curva de acúmulo de massa seca total como o ponto de inflexão $(b=55,9)$, ou seja, aos 56 DAS, observou-se no capim-camalote a maior diferença no acúmulo de massa entre duas avaliações, provavelmente por conseqüência do crescimento dos perfilhos e da intensa formação de inflorescências.

Com relação ao desenvolvimento vegetativo dessa planta daninha, três outros aspectos devem ser comentados: (a) na parte basal da estrutura vegetativa observou-se intensa emissão de vigorosas raízes adventícias originadas dos primeiros nós dos colmos, localizados acima do nível do vaso, que inicialmente auxiliaram na sustentação da planta e, posteriormente, também, apresentaram estruturas para absorção; (b) os perfilhos mais desenvolvidos por vezes tendiam ao tombamento e, quando os primeiros nós dos colmos aproximavam-se da superfície do vaso, também havia formação de raízes adventícias; (c) em diversas plantas, os nós superiores dos colmos possuíam simultaneamente racemos florais e ramos vegetativos e, quando os rácemos maduros foram colhidos, observou-se nova emissão de inflorescências.

Segundo BAKER (1974), uma das principais características que conferem o sucesso de uma planta daninha ao colonizar uma área agrícola é a capacidade da espécie em produzir e dispersar sementes durante todo o seu ciclo de vida. Assim, realizou-se o acompanhamento quanto à emissão dos racemos florais ao longo do ciclo das plantas. De forma acumulada, uma única planta de capimcamalote foi capaz de emitir até 208 racemos; contudo a média manteve-se em $163 \pm 6,18$ racemos. A contagem de 100 rácemos indicou a formação de, em média, $12,3 \pm 0,11$ artículos por racemo. Extrapolando-se os resultados obtidos, pôde-se estimar que as plantas foram capazes de produzir, durante um período de 90 dias, um total de aproximadamente 2005 sementes.

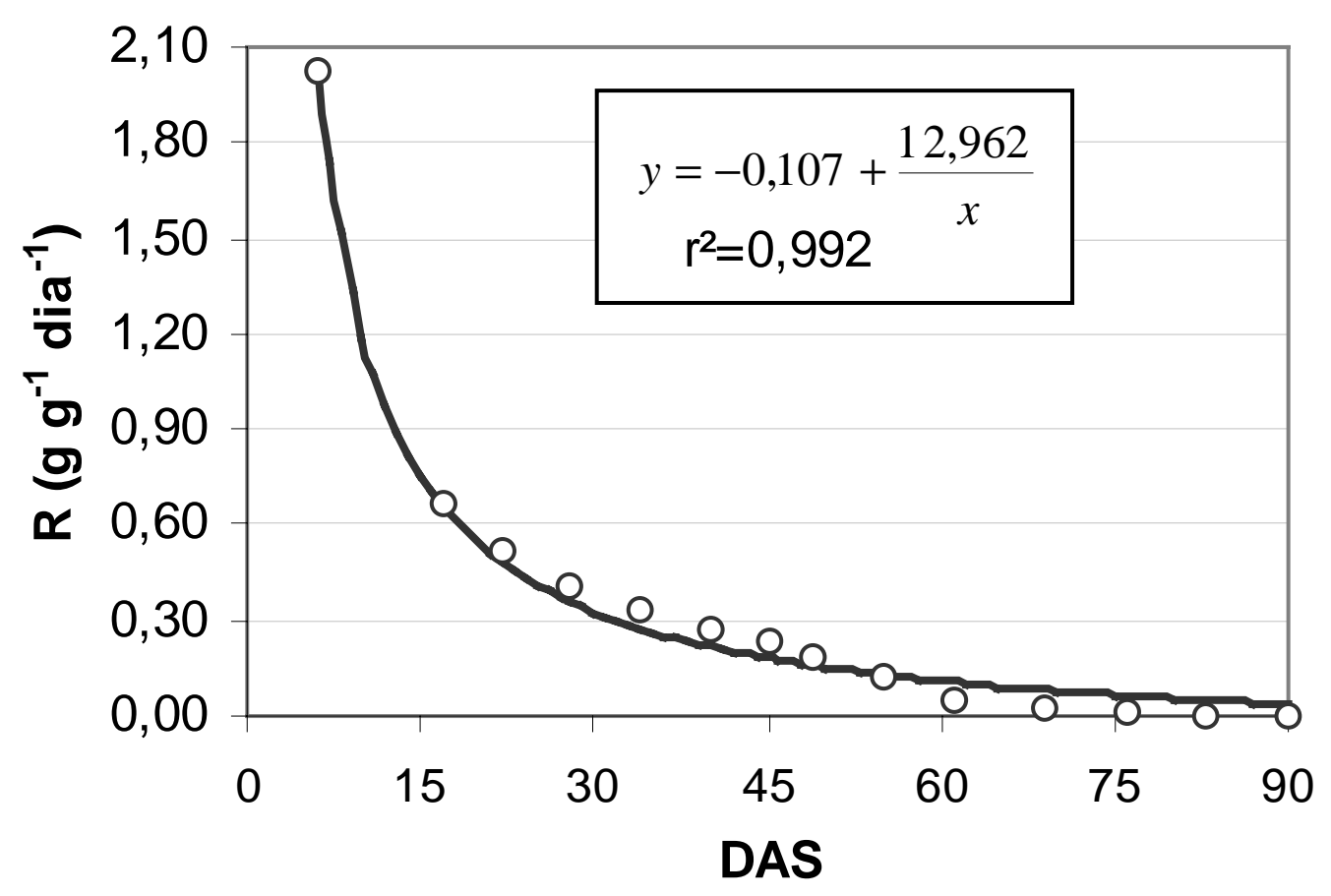

Figura 4. Taxa de crescimento relativo (R) das plantas de Rottboelia exaltata ao longo de seu ciclo de desenvolvimento. Piracicaba (SP), 2004. 


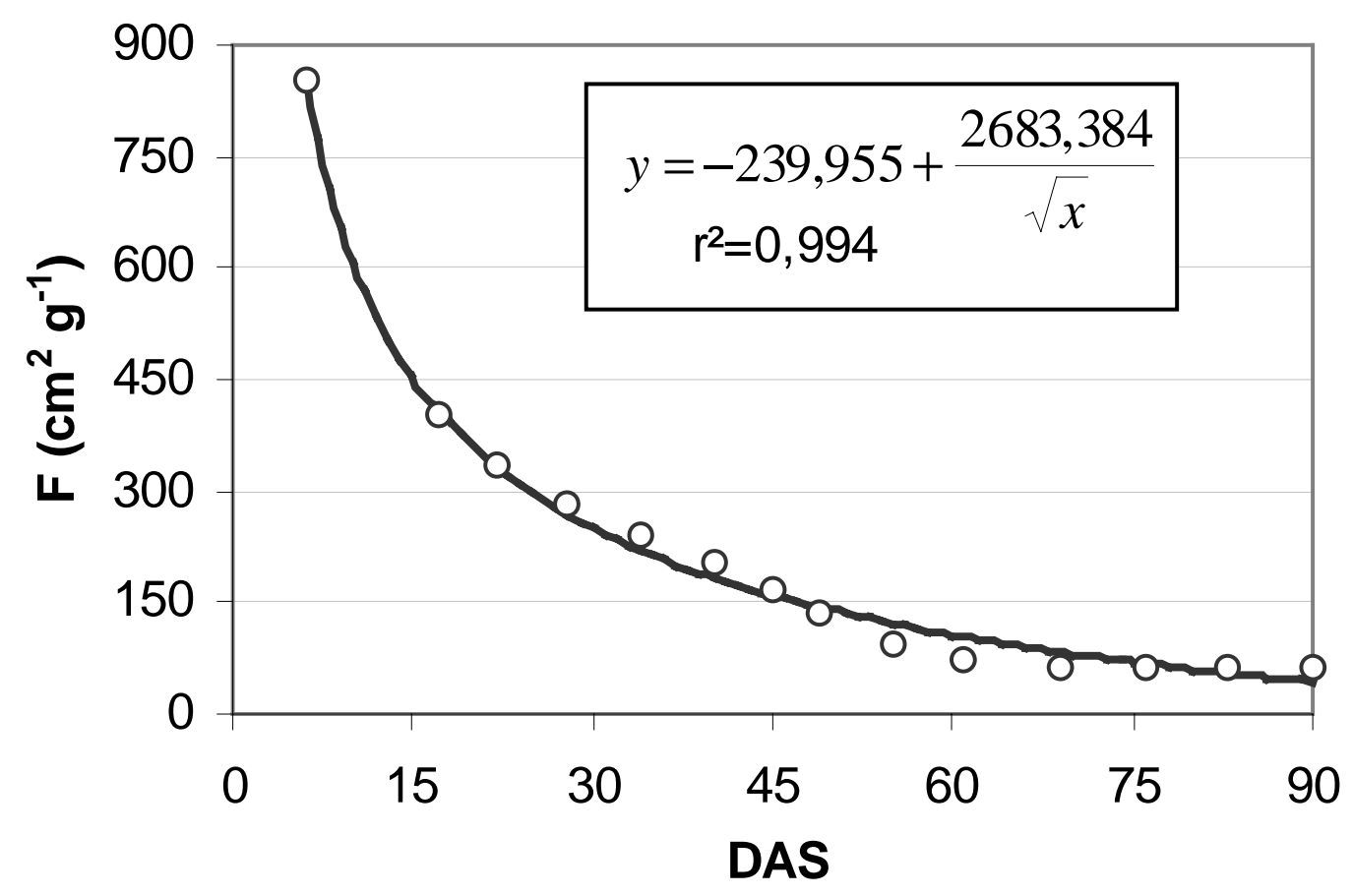

Figura 5. Razão de área foliar (L) das plantas de Rottboelia exaltata ao longo de seu ciclo de desenvolvimento. Piracicaba (SP), 2004.

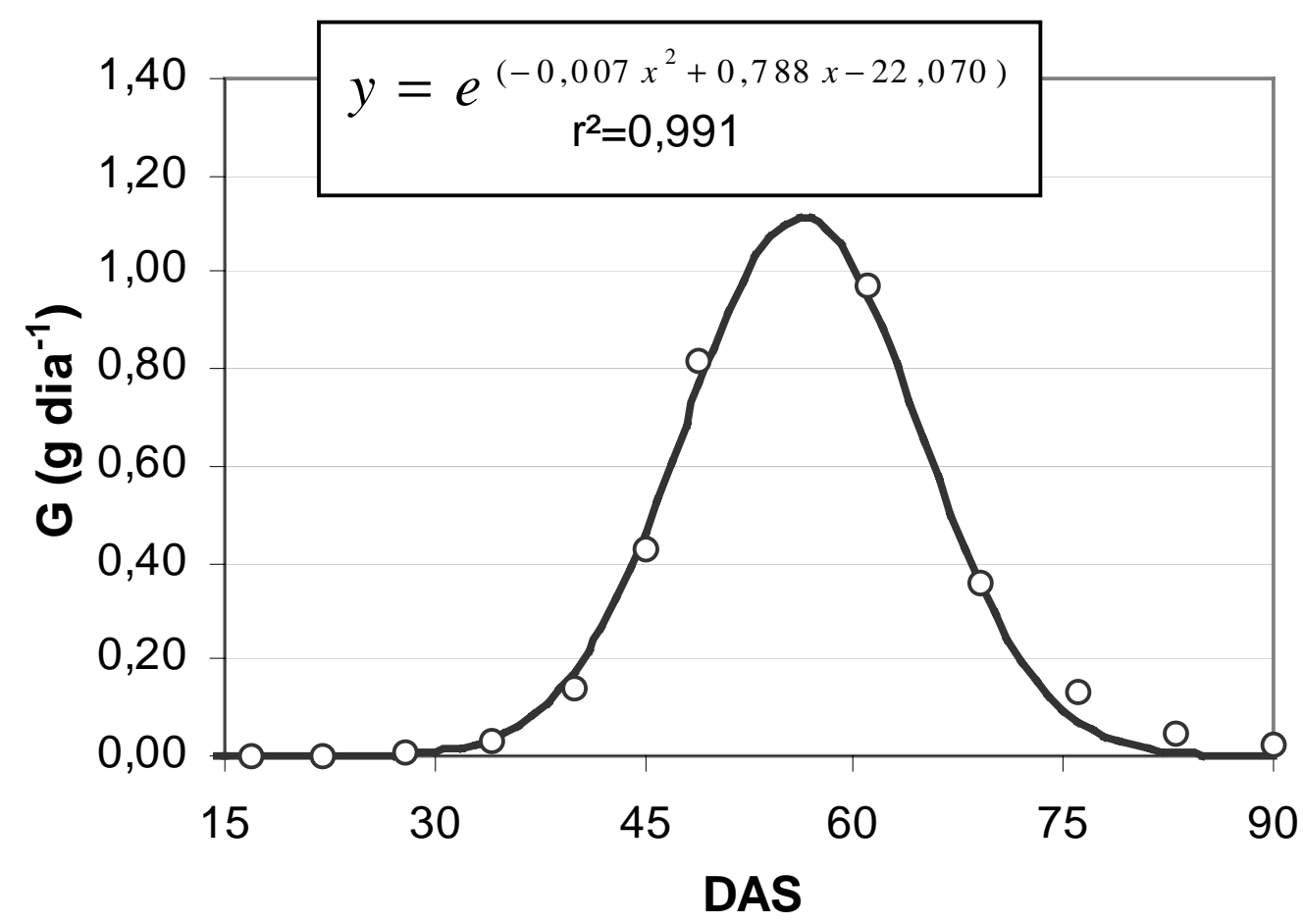

Figura 6. Taxa de crescimento absoluto (G) das plantas de Rottboelia exaltata ao longo de seu ciclo de desenvolvimento. Piracicaba (SP), 2004. 
O florescimento do capim-camalote está diretamente relacionado com fotoperiodismo, ocorrendo quando o número de horas diárias de luz é menor que 13; para o Estado de São Paulo, o florescimento se dá nos meses de verão (Kissmann, 1997). Essa informação pode justificar a menor formação de racemos florais, menor número de artículos por racemo e, conseqüentemente, de sementes, quando comparado com os dados de Arévalo e Bertoncini (1994) para a localidade de Tucumán $\left(27^{\circ} 46^{\prime}\right.$ L.S.), na Argentina, uma vez que os valores de massa seca são similares.

Existem alguns relatos que indicam a ocorrência de intenso polimorfismo na espécie, correlacionado com a existência de poliploidia e, por conseqüência, têm-se a adaptação de biótipos às mais variadas condições ambientais (KISSMANN, 1997; Millhollon e Burner, 1993). Essa habilidade das plantas pode promover o gradativo incremento na adaptação da espécie à condição dos canaviais paulistas e, por analogia, a outras culturas agrícolas brasileiras, por vezes menos competitivas que a canade-açúcar, o que pode resultar no agravamento do problema existente.

O manejo dessa planta daninha precisa ser estruturado com base nos conhecimentos do crescimento e desenvolvimento da espécie, ou seja, as medidas de controle devem ser administradas em período anterior a, aproximadamente, 40 dias de desenvolvimento das plantas, pois a partir deste ponto, pode ocorrer o florescimento com rápida dispersão de sementes ao solo. Da mesma forma, o crescimento inicial rápido exige que medidas de manejo sejam realizadas sobre plantas jovens para que os melhores resultados sejam obtidos, uma vez que o desenvolvimento da planta dificulta o controle; e, também, para que a competição entre a planta daninha e a cana-deaçúcar não ocorra ou mesmo que não seja significativa sobre a produção.

Em aspectos gerais, observou-se que o capimcamalote é uma planta daninha com vigoroso crescimento vegetativo e rápido ciclo reprodutivo, uma vez que aos 49 DAS iniciou seu florescimento e conseqüente produção de sementes. É uma espécie bastante vigorosa quanto à ocupação do espaço e de rápido crescimento, altamente capaz em emitir estruturas reprodutivas e produzir propágulos ao longo de todo o seu ciclo, sendo também muito oportunista quanto ao seu processo de enraizamento; características que explicam as razões que fazem dessa planta daninha um novo problema em potencial para a agricultura brasileira.

\section{AGRADECIMENTOS}

Os autores agradecem o Prof. Quirino Augusto de Camargo Carmello, do Departamento de Solos e Nutrição de Plantas - ESALQ/USP, por ter colaborado para a realização deste trabalho.

\section{REFERÊNCIAS}

AGUILERA, D.B.; FERREIRA, F.A.; CECON, P.R. Crescimento de Siegesbeckia orientalis sob diferentes condições de luminosidade. Planta Daninha, Viçosa, v.22, n.1, p. 43-51, 2004.

ARÉVALO, R.A. Matoecologia da cana-de-açúcar. São Paulo, SP: Ciba-Geigy, 1979. 16p.

ARÉVALO, R.A.; BERTONCINI, E. Biologia e manejo de Rottboelia exaltata L.f. na cultura da cana-de-açúcar Saccharum spp.: Análise do problema. Piracicaba: Estação Experimental de Cana-de-açúcar/IAC, 1994. 24p. (Publicação Especial Centro de Cana Piracicaba. n.2)

BAKER, H. The evolution of weeds. Annual Review of Ecology System, v.5, p.1-24, 1974.

BENINCASA, M.M.P. Análise de crescimento de plantas: noções básicas. Jaboticabal: FUNEP, 1988. 42p.

BIANCO, S.; BARBOSA JUNIOR, A.F.; PITELLI, R.A. Crescimento e nutrição mineral de capim-camalote. Planta Daninha, Viçosa, v.22, n.3, p.375-380, 2004.

FERNÁNDEZ, O.A. Manejo integrado de malezas. Planta Daninha, Viçosa, v.5, n.2, p. 69-75, 1982.

HOLM, L.G.; PLUCKNETT, D.L.; PANCHO, J.V.; HERBERGER, J.P. The world's worst weeds: Distrbution and biology. Honolulu: The East-west Center by the University Press of Hawaii, 1977. 609p.

HUNT, R. Basic growth analysis: plant growth analysis for beginners. London: Unwin Hyman, 1990. 112p.

KISSMANN, C.G. Plantas infestantes e nocivas. t.I - Plantas inferiores; monocotiledôneas $-2^{\mathrm{a}}$. ed. São Paulo: BASF, 1997. 825p.

KUVA, M.A.; PITELLI, R.A.; CHRISTOFFOLETI, P.J.; ALVES, P.L.C.A. Períodos de interferência das plantas daninhas na cultura da cana-de-açúcar. I- tiririca. Planta Daninha, Viçosa, v.18, n.2, p. 241-251, 2000.

LORENZI, H. Plantas daninhas e seu controle na cana-deaçúcar. In: REUNIÃO TÉCNICA AGRONÔMICA, 1983, Piracicaba. Anais... São Paulo: COPERSUCAR, 1983. p. 59-73.

LORENZI, H. Plantas daninhas e seu controle na cultura da cana-de-açúcar. In: IV SEMINÁRIO DE TECNOLOGIA AGRONÔMICA, 4, 1988. Piracicaba. Anais... São Paulo: COPERSUCAR, 1988. p. 281-301. 
LORENZI, H. Plantas daninhas do Brasil: terrestres, aquáticas, parasitas e tóxicas. $3^{\text {a }}$. ed. Nova Odessa, SP: Instituto Plantarum, 2000. 608p.

LUCCHESI, A.A. Utilização prática de análise de crescimento vegetal. AM. ESALQ. Piracicaba: v. 41, p. 181-202. 1984

MILLHOLLON, R.W.; BURNER, D.M. Itchgrass (Rottboelia exaltata L.) biotypes in world populations. Weed Science, Champaign, v.41, n.3, p. 379-387, 1993.

OLIVER, D. Importance of weed biology to weed management: proceedings of a symposium presented at the Weed Science
Society of America Meeting in Norfolk, Virginia, Febraury 6, 1996. Weed Science, Champaign v. 45, n.3, p. 328. 1997.

PAUL, R.; ELMORE, C.D. Weeds and the C4 syndrome. Weeds Today, v. 15, n.1, p. 3-4, 1984.

RADOSEVICH, S.; HOLT, J.S.; GHERSA, C. Weed Ecology: implications for vegetation management. New York: John Wiley and Sons, 1997. 589p.

STREIBIG, J.C. Herbicide bioassay. Weed Research, Oxford, v.28, n.6, p.479-484, 1988. 